\title{
CdHgTe Quantum Dots Sensitized Solar Cell with Using of Titanium Dioxide Nanotubes
}

\author{
M. Y. Feteha, M. Ameen \\ Department of Materials Science, Institute of Graduate Studies and Research, Alexandria University, Alexandria, Egypt. \\ Email: FETEHA99@yahoo.com
}

Received September 2013

\begin{abstract}
The sensitization of $\mathrm{TiO}_{2}$ nanotubes with CdHgTe quantum dots (QDs) was applied by using the direct dispersion technique. The CdHgTe-QDs were fabricated with different $\mathrm{Hg} \%$ ratio in organic medium for controlling their particle size. While $\mathrm{TiO}_{2}$ nanotubes (NTs) were fabricated by anodization technique. The QDs and NTs were characterized using SEM, TEM and UV-VIS spectrophotometer. In this work, the photovoltaic parameters of the quantum dots sensitized solar cell (QDSSC) depend mainly on the Hg\% ratio in the QDs. The most efficient QDSSC was obtained at 25\% of $\mathrm{Hg}$ ratio with $\mathrm{J}_{\mathrm{sc}}$ of $4 \mathrm{~mA} / \mathrm{cm}^{2}, \mathrm{~V}_{\mathrm{oc}}$ of $0.63 \mathrm{~V}$, FF of 0.32 and efficiency of $0.81 \%$.
\end{abstract}

Keywords: Solar Cells; Quantum Dots; Nano-Tubes; $\mathrm{TiO}_{2}$; Sensitization

\section{Introduction}

Quantum dots photovoltaic cells combine low-cost solution process-ability with quantum size-effect tunability to match absorption with the solar spectrum [1]. Relative to the dyes used in solar cells, QDs offer several advantages such as photo-stability, greater molar extinction coefficients, and size-dependent optical properties [2]. They also have the potential to increase the maximum attainable thermodynamic conversion efficiency of solar photon conversion up to $66 \%$ by utilizing hot photo-generated carriers to produce higher photo-voltages or higher photocurrents via multi-exciton generation capability. While the charge carriers are confined within an infinitesimal volume, thereby increasing their interactions and enhancing the probability for multiple exciton generation [3,4]. The calculations of the dependence of ideal solar cell conversion efficiency on band gap show that CdTe is an excellent match to our sun $[5,6]$.

In order to control the CdTe QDs band gap, mercury was added to the preparation medium [2]. The key challenge with such cells, the quantum dot sensitized solar cells (QDSSCs), is the relatively low absorption cross section of the QDs [6]. Titania nanotubes (TNTs) present the key solution for carrier's recombination and low absorption issues via the highly ordered nano-structured matrix which provides continuous electron pathways to facilitate a good electrons collection with high surface area [7].

$\mathrm{TiO}_{2}$ nanotubes arrays and particulate films were modified with CdS quantum dots with an aim to tune the re- sponse of the photo-electrochemical cell in the visible region via successive ionic layer adsorption and reaction (SILAR) [8].

The QDSSCs were fabricated by incorporating CdHgTe nanocrystals (NCs) and CdTe quantum dots, which prepared separately from aqueous mixtures of NaHTe, $\mathrm{Cd}\left(\mathrm{NO}_{3}\right)_{2}$, and 3-mercaptopropionic acid in the presence and absence of $\mathrm{HgCl}_{2}$ respectively, then the sensitization of a modified $\mathrm{TiO}_{2}$ nanoparticles was carried out to obtain an energy conversion efficiencies of $1.0 \%$ and $2.2 \%$ [2].

In this work, the sensitization of $\mathrm{TiO}_{2}$ nanotubes-prepared with anodization method-with CdHgTe-QDs-prepared with organic method-was applied by direct dispersion. The aim of the present work is to enhance the QDSSCs efficiency by tuning the energy gab of the CdHgTe-QDs with changing $\mathrm{Hg} \%$ ratio. The effect of $\mathrm{Hg}$ ratio in the QDs on the photovoltaic parameters of the QDSSC was investigated.

\section{Experimental Work}

\subsection{Materials}

Ti foil (99.7\% B.D.H., England), Ethylene Glycol (Nice chemicals, India), Ammonium fluoride (oxford, India), Acetic Acid (99.9\%, fluka, Germany), De-ionized water (DI), Cadmium acetate (MP Biomedicals), Tellurium powder (99\%, Aldrich), Octadecene (Acros), Trioctylphosphine (TOP) (99\%Acros), Oleic acid (99\%, Aldrich), Mercury Chloride, Isopropanol (Aldrich) and n-hexane 
(Aldrich) were used for fabricating the CdHgTe QDs$\mathrm{TiO}_{2}$ nanotubes solar cells.

\subsection{Preparation of $\mathrm{TiO}_{2}$ Nanotubes}

Titania nanotubes were prepared by the electrochemical anodizing of Ti foil which was ultrasonically degreased with a mixture of Acetone, Methanol and Ethanol then rinsed with DI water and dried with nitrogen. The anodization process was carried out in an electrochemical cell with two electrodes model where the titanium is the anode and platinum wire is the counter electrode (the cathode). The anodization electrolyte was a mixture of Ethylene Glycol, Ammonium fluoride (0.5\%wt), Acetic acid (for $\mathrm{pH}$ adjustment) and DI water (2\% volume). All experiments were carried out at room temperature $\left(25^{\circ} \mathrm{C}\right)$ and the anodizing voltage was $40 \mathrm{~V}$ and applied for 3 hours. Once the process completed, the anodized sample removed from the cell and washed with a large amount of water then dried with nitrogen. The Ti electrode was annealed in air at $500^{\circ} \mathrm{C}$ for 3 hours in order to improve Anatase phase. The morphology (i.e. length, diameter, and the shape) of the $\mathrm{TiO}_{2}$ nanotubes was investigated by the scanning electron microscope (SEM: Joel Jsm 6360 LA, Japan).

\subsection{Preparation of CdTe and CdHgTe QDs}

Tellurium powder $(0.127 \mathrm{gm})$ was added to triocytlphosphine (TOP, $2 \mathrm{ml})$ and Octadecene $(8 \mathrm{ml})$ with stirring at $60^{\circ} \mathrm{C}$ for $30 \mathrm{~min}$. till giving the greenish gray color with a complete dissolving. In a three neck rounded flask, Cadmium acetate $(0.186 \mathrm{gm})$ was mixed with Oleic acid $(2 \mathrm{ml})$ and Octadecene $(5 \mathrm{ml})$ and then rising the temperature up to $80^{\circ} \mathrm{C}$. The tellurium precursor was added to the above cadmium solution at $80^{\circ} \mathrm{C}$. To synthesis CdHgTe QDs from organic medium, mercury chloride was added to above cadmium solution. The CdTe and CdHgTe QDs were separated in Isopropanol via centrifuge at $5000 \mathrm{rpm}$. These QDs were dissolved again in n-hexane to prepare the sensitization solution. UV-visible characterization of the CdHgTe QDs solution was carried out using Thermo-Evolution 600 spectrophotometer and the HRTEM images of the QDs were obtained using JEOL (JEM-2100 LaB6) TEM.

\subsection{Preparation of Quantum Dot Sensitized Solar Cell (QDSSC)}

The prepared nanotubes electrodes were immersed into the QDs/N-Hexane suspension. Then left for 3 days with sonication every 12 hours in airtight tubes to ensure a good QDs diffusion through the TNTs layer.

The QD sensitized solar cells with a structure of ITO/ liquid electrolyte/CdHgTe-QDs/TiO ${ }_{2}$ (NTs)/Ti were assembled as shown in Figure 1. The sensitized Ti-TNTs

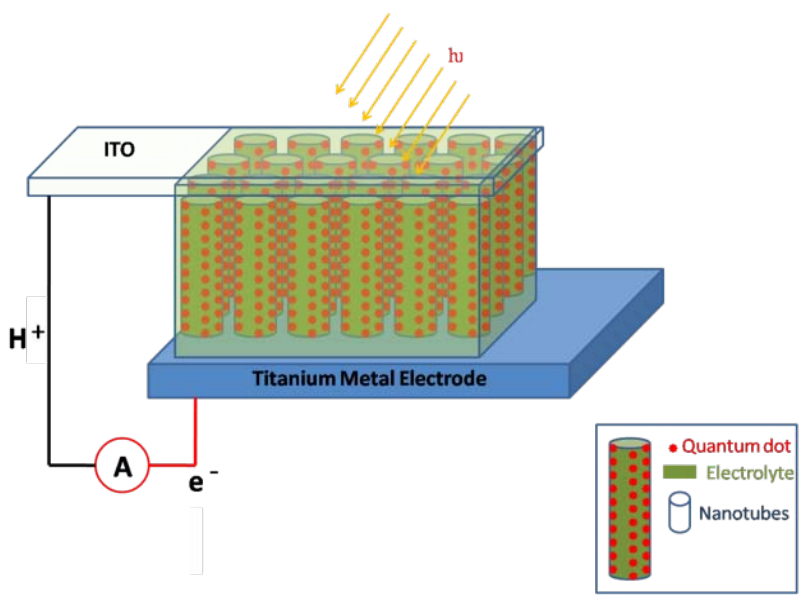

Figure 1. QDSSC assembly.

is the working electrode and a carbon activated indium tin oxide (ITO, $\mathrm{R}=14-16 \Omega$ ) is the other electrode. The two electrodes were spaced by a polymeric spacer with $50 \mu \mathrm{m}$ thickness. The Redox electrolyte was injected through the cell's sides.

All cells were illuminated by using Xenon lamp with an intensity of $100 \mathrm{~m} \mathrm{~W} / \mathrm{cm}^{2}$ (AM1.5). The lamp was calibrated with Solarex standard solar cell and the J-V measurements were obtained by using Keithley 2635A source-meter.

\section{Results and Discussion}

\subsection{Characterization of $\mathrm{TiO}_{2}-\mathrm{NTs}$}

Images of scanning electron microscope (SEM) for the anodized titanium show a highly ordered, smooth, and dense packed Titania nanotubes formed at $40 \mathrm{~V}$ for $3 \mathrm{~h}$ in Ethylene glycol/ammonium fluoride electrolyte. The obtained nanotubes having an average outer diameter of 75 $\mathrm{nm}$ and a wall thickness in the range of $10-14 \mathrm{~nm}$ while the tubular layer thickness was around $24 \mu \mathrm{m}$ (as shown in Figure 2) which provides a naturally n-type semiconductor with a relatively high surface area with a $3.2 \mathrm{eV}$ band gap (after annealing) referred to the anatase crystal structure [9].

The arrangement of the highly ordered Titania nanotubes array perpendicular to the surface permits a facile charge transfer along the length of the nanotubes to the conductive substrate [10]. The prepared nanotubes may resolve the problem of relatively low absorption cross section of the QDs by increasing the area of contacts in addition with the appropriate layer thickness which expected to increase the solar cell performance.

\subsection{Characterization of CdHgTe QDs}

\subsubsection{UV-Vis. Spectroscopy}

Figure 3 presents the UV-visible spectra of CdHgTe 


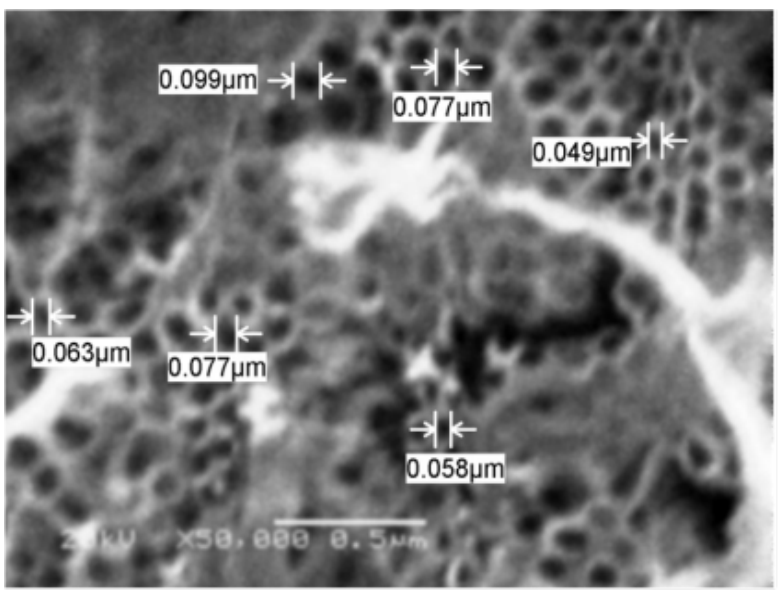

(a)

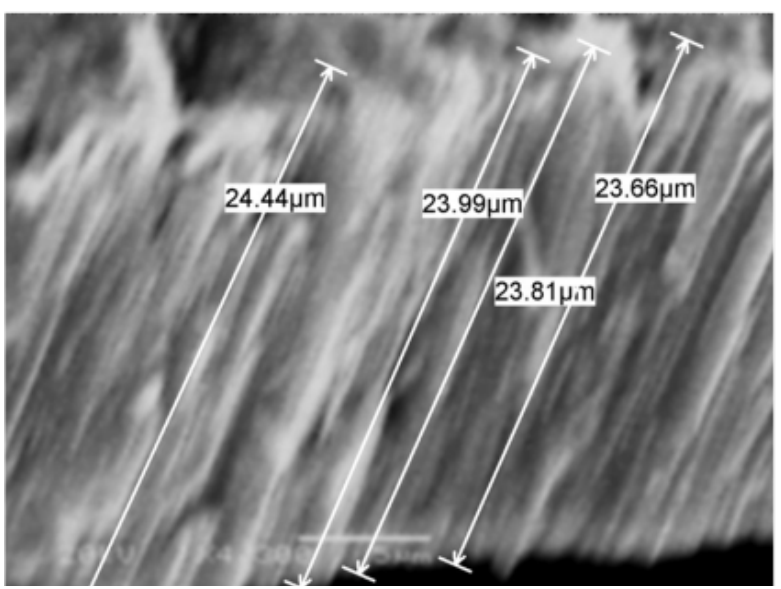

(c)

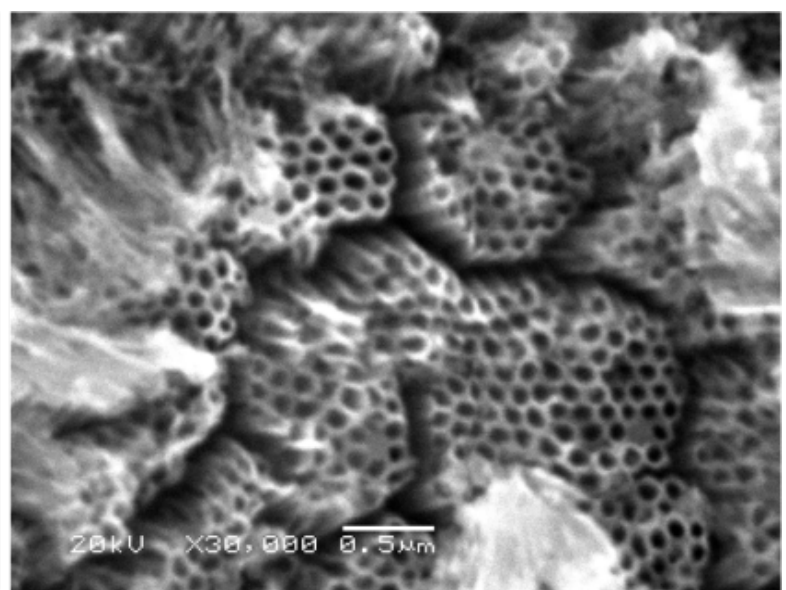

(b)

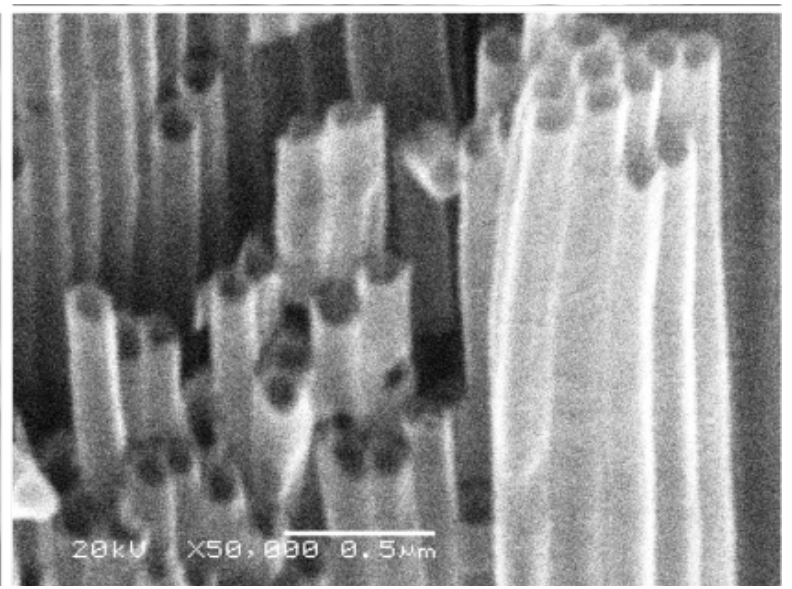

(d)

Figure 2. SEM images for a sample anodized at $40 \mathrm{~V}$ for $3 \mathrm{~h}$ in Ethylene Glycol: (a) and (b)Top views;(c) Side view; and (d) Side view at higher magnification.

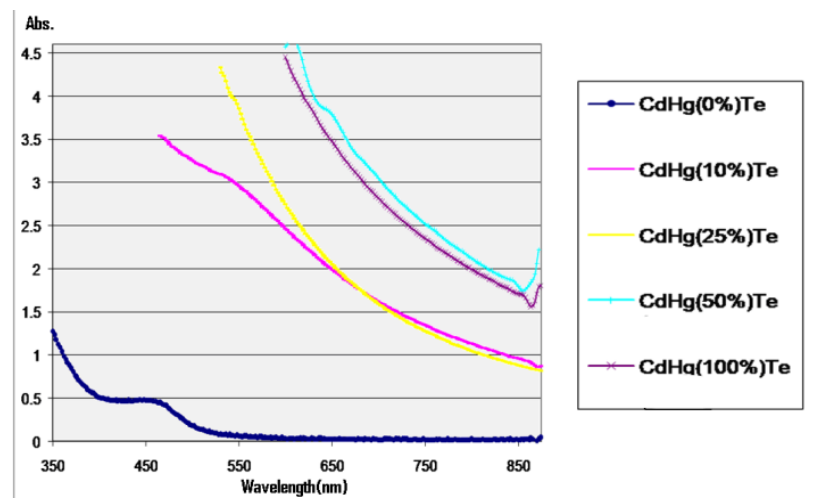

Figure 3. UV-visible absorption spectra of CdHgTe QDs prepared with different ratios of mercury. The obtained curves are similar to those reported in the previous work [12].

QDs prepared using organic medium at different ratios of Hg. For CdTe sample, the absorption peak is around 460 $\mathrm{nm}$ indicating the formation of CdTe QDs [11]. It was noted that as the relative concentration of mercury in- creases, the excitonic absorption peak of CdTe QDs shifts to the longer wavelengths from $460 \mathrm{~nm}$ (for $0 \%$ of $\mathrm{Hg}$ ) to $855 \mathrm{~nm}$ (for $100 \% \mathrm{Hg}$ ) due to the quantum confinement effect as the QDs grow to larger size and this is a good evidence for the formation of CdHgTe QDs [12].

The $\mathrm{Hg}^{2+}$ ions substitute $\mathrm{Cd}^{2+}$ ions at the surface of the nanocrystals forming a CdHgTe alloy in the near-surface region, possibly with a concentration gradient decreasing towards the dot interior [11].

Using the absorption spectrum, the direct optical band gap energy of the QDs was calculated by simply plotting $(\alpha h v)^{2}$ versus $(h v)$, obtained from the following relation [11]:

$$
\alpha \mathrm{h} v=\mathrm{A}(\mathrm{h} v-\mathrm{Eg})^{1 / 2}
$$

Where $\alpha$ and A are the absorption coefficient and a constant respectively. The direct optical band energy gap of the CdHgTe QDs was calculated to be 2.3, 1.62, 1.5, 1.35 and $1.3 \mathrm{eV}$ for $0,10,25,50$, and $100 \%$ ratio of $\mathrm{Hg}$, respectively. The decrease in the optical band gap with increasing the Hg percentage is regarded to the formation 
of a layer of HgTe on the QDs surface [12].

\subsubsection{High Resolution Transmission Electron Microscope (HRTEM)}

Figure 4 shows HRTEM images of CdHgTe QDs prepared using organic medium with different ratios of $\mathrm{Hg}$. The existence of the lattice planes in the HRTEM images indicates that the QDs are highly crystalline as shown in the white circles mentioned in Figure 4. It was noted that the increase in $\mathrm{Hg} \%$ ratio from 0 to 10, 25, 50 and 100 leads to an increase in the size of QDs from 2.8 to 8.6, 9, 9.5 and $10.8 \mathrm{~nm}$ respectively. This is due to the formation of a HgTe layer on the surface [12].

\subsection{Characterization of $\mathrm{TiO}_{2}-\mathrm{NTs}$ (TNTs)/CdHgTe Quantum Dots Solar Cells (QDSSCs)}

The SEM images (Figure 5) showed fully covered TNTs
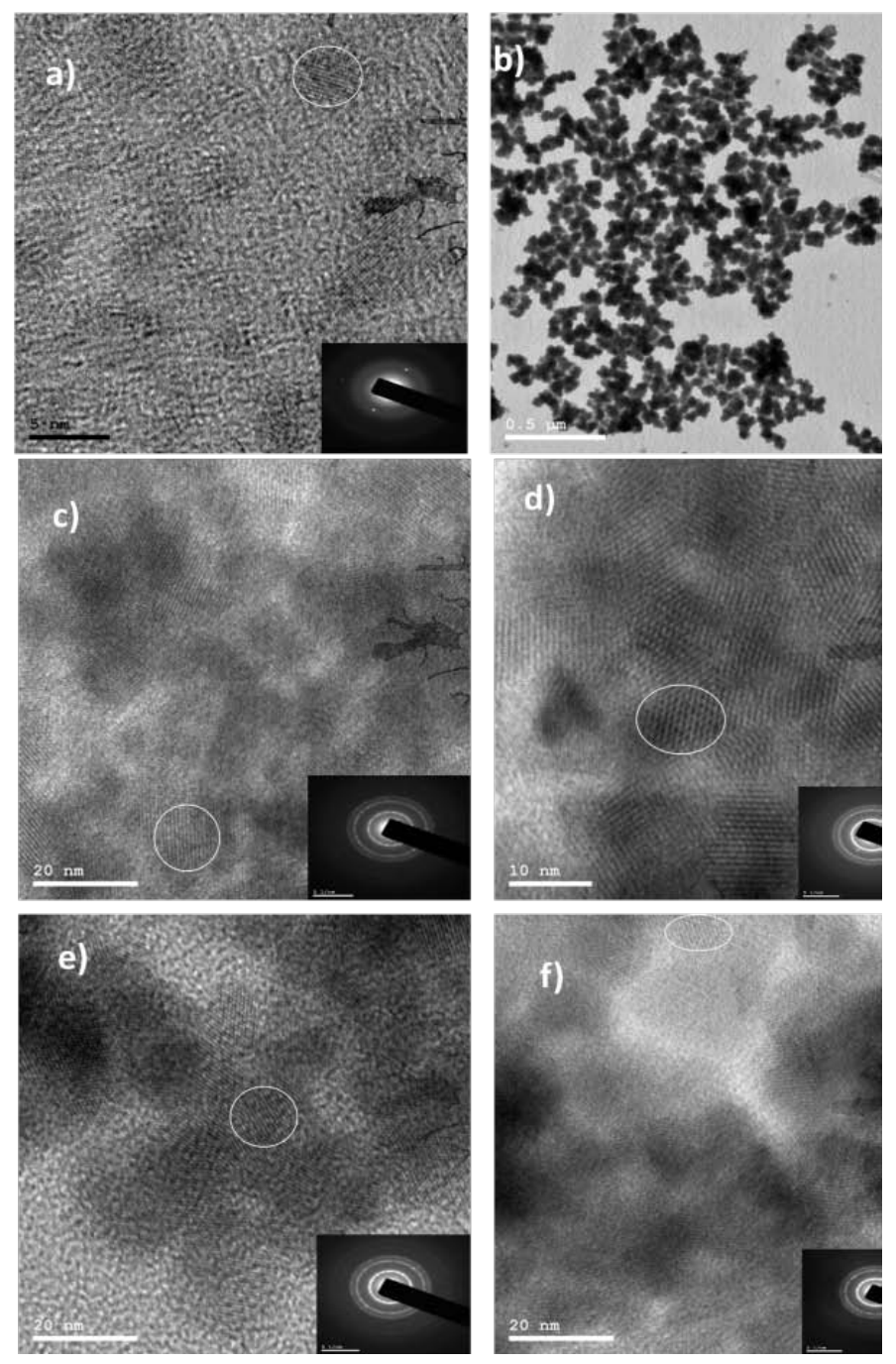

Figure 4. HRTEM images of colloidal CdHgTe solution prepared using organic method. (a) $0 \% \mathrm{of} \mathrm{Hg}$, (b) $10 \%$ of $\mathrm{Hg}$ at low magnification, (c) $10 \%$ of $\mathrm{Hg}$ at higher magnification, (d) $25 \% \mathrm{of} \mathrm{Hg}$, (e) $50 \% \mathrm{Hg}$, and (f) $100 \% \mathrm{Hg}$. 

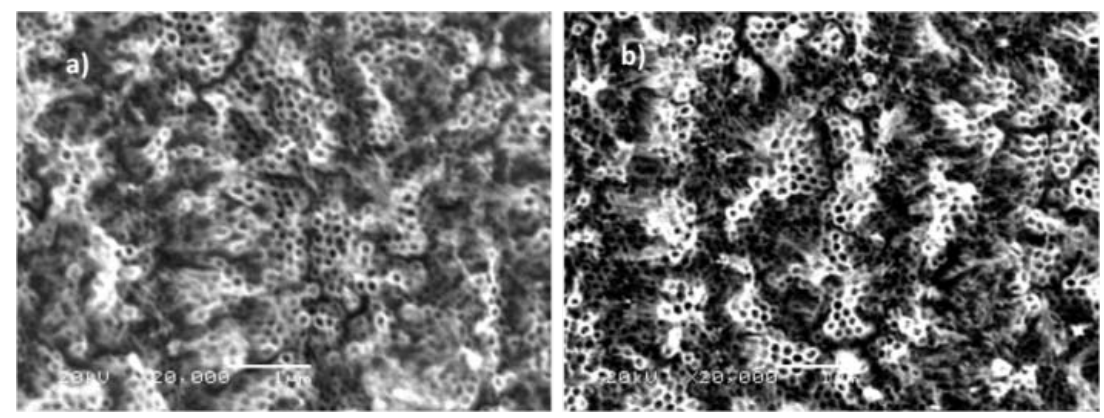

Figure 5. SEM images of Titania nanotubes after sensitization: a) Top view for a sample sensitized with CdHgTe QDs, b) Top view of a sample sensitized with CdTe QDs.

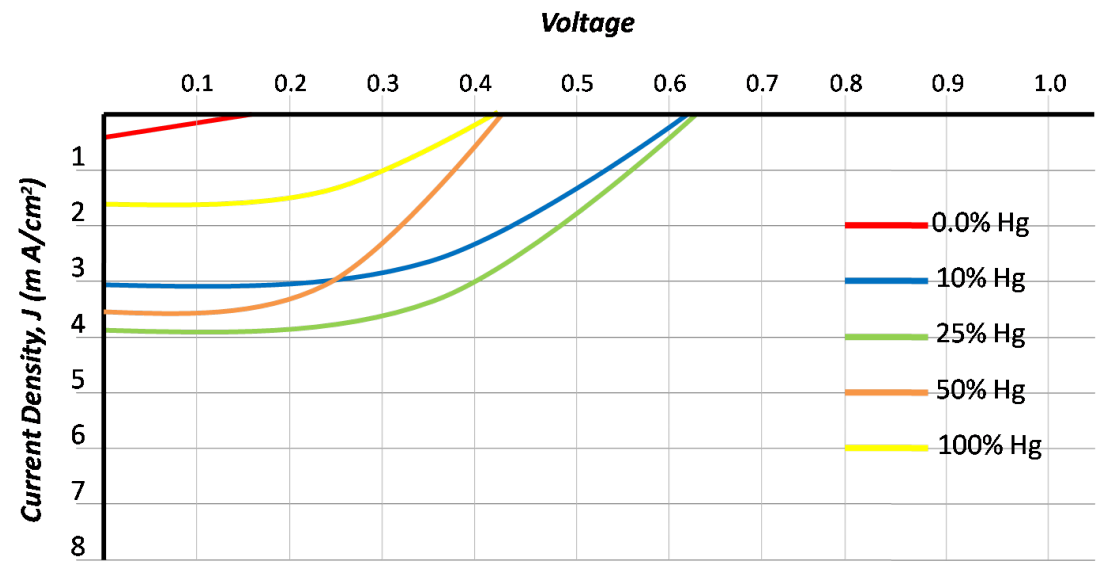

Figure 6. J-V characteristic curves of $\mathrm{TiO}_{2}-\mathrm{NTs} / \mathrm{CdHgTe}-\mathrm{QDs}$ sensitized solar cell with different $\mathrm{Hg} \%$ ratios.

Table 1. Photovoltaic parameters of the prepared QDSSCs.

\begin{tabular}{cccccc}
\hline & CdHgTe $(0 \% \mathrm{Hg})$ & CdHgTe $(10 \% \mathrm{Hg})$ & CdHgTe $(25 \% \mathrm{Hg})$ & CdHgTe $(50 \% \mathrm{Hg})$ & $\mathrm{CdHgTe}(100 \% \mathrm{Hg})$ \\
\hline Particle size $(\mathrm{nm})$ & 3.5 & 8.5 & 9 & 9.5 & 10.5 \\
$\mathrm{E}_{\mathrm{g}}(\mathrm{eV})$ & 2.3 & 1.62 & 1.5 & 4.35 & 1.3 \\
$\mathrm{~J}_{\mathrm{sc}}\left(\mathrm{mA} / \mathrm{cm}^{2}\right)$ & 0.4 & 3.1 & 0.6 & 3.6 & 1.7 \\
$\mathrm{~V}_{\mathrm{oc}}(\mathrm{V})$ & 0.15 & 0.61 & 0.63 & 0.43 & 0.41 \\
$\mathrm{FF}$ & 0.18 & 0.23 & 0.32 & 0.34 & 0.2 \\
Efficiency\% & 0.012 & 0.435 & 0.81 & 0.53 & 0.14 \\
\hline
\end{tabular}

this value (i.e. $1.5 \mathrm{eV}$ ). This result up to $1.5 \mathrm{eV}$ is due to the excited state of the QD lies well above the $\mathrm{TiO}_{2}$ conduction band level and photo-excited electrons injection into $\mathrm{TiO}_{2}$ would be energetically favorable[1]. While, by increasing the band gap ( $>1.5 \mathrm{eV})$, the hole level exhibits a large discontinuity with the $\mathrm{TiO}_{2}$ valence band, providing a very large barrier to the undesired passage of majority holes from the p-type QD layer into the n-type $\mathrm{TiO}_{2}$ electrode [1].

Additionally, $\mathrm{V}_{\mathrm{oc}}$ and $\mathrm{J}_{\mathrm{sc}}$ values were dramatically dropping by increasing the $\mathrm{Hg} \%$ ratio from $25 \%$ to $100 \%$. This behavior can be explained by another cause which is regarded to the distorted QDs structure with an access of mercury concentrations. When the $\mathrm{Hg} \%$ ratio increased, $\mathrm{Hg}^{2+}$ ions should be substituted at the surface of the na- nocrystals, and in theory, if complete surface exchange occurs, a core/single-monolayer-shell structure will result [12]. The substitution reaction then completes either due to an exhaustion of $\mathrm{Hg}$ ions in solution or because of the formation of a complete "locking" layer of HgTe on the surface. And finally the outer layer forms an almost perfectly passivated quantum dot [12].

From another point of view, the obtained J-V curves suffering from a bad fill factor due to the high series resistance of cell and moreover the spacer issue which is a strong factor that may reduce the cell efficiency. On the other hand, the performance of the prepared solar cell in this work can be enhanced in further work using a better sensitization technique, better sealing conditions and by the usage of a linker. 


\section{Conclusions}

The direct dispersion technique was used for fabricating CdHgTe-QDs sensitized $\mathrm{TiO}_{2}$-NTs solar cells with different $\mathrm{Hg} \%$ ratios in QDs. The obtained highly ordered and dense packed Titania nanotubes were having an average outer diameter of $75 \mathrm{~nm}$ and a layer thickness of 24 $\mu \mathrm{m}$. In addition, the direct energy gap of the highly crystalline CdHgTe QDs was calculated to be 2.3, 1.62, 1.5, 1.35 and $1.3 \mathrm{eV}$ for $0 \%, 10 \%, 25 \%, 50 \%$, and $100 \%$ ratio of $\mathrm{Hg}$ respectively.

The increase in $\mathrm{V}_{\mathrm{oc}}$ and $\mathrm{J}_{\mathrm{sc}}$ values corresponding to a change in $\mathrm{Hg} \%$ ratio from $0 \%$ to $25 \%$ was due to the absorption enhancement in IR region while the decrease in $\mathrm{V}_{\mathrm{oc}}$ and $\mathrm{J}_{\mathrm{sc}}$ values corresponding to a change in $\mathrm{Hg}$ ratio from $25 \%$ to $100 \%$ was due to either the discontinuity in the energy level or the formation of locking layer of HgTe on the QDs surface. The most efficient QDSSC was obtained at $25 \%$ of $\mathrm{Hg}$ ratio with $\mathrm{J}_{\mathrm{sc}}$ of $4 \mathrm{~mA} / \mathrm{cm}^{2}$, $\mathrm{V}_{\mathrm{oc}}$ of $0.63 \mathrm{~V}$, FF of 0.32 and efficiency of $0.81 \%$.

The performance of the QDSSC mentioned in this work can be enhanced using a better sensitization technique, better sealing conditions and by the usage of a linker.

\section{Acknowledgements}

The authors are very grateful to the research team of the US-Egypt project chaired by Prof. Moataz Soliman for the funding support and the research student: Wessam Kamal for her help in preparing the materials.

\section{REFERENCES}

[1] A. G. Pattantyus-Abraham, I. J. Kramer, A. R. Barkhouse, X. Wang, G. Konstantatos, R. Debnath, L. Levina, I. Raabe, M. K. Nazeeruddin, M. Grätzel and E. H. Sargent, "Depleted-Heterojunction Colloidal Quantum Dot Solar Cells,” ACS Nano, Vol. 4, No. 6, 2010, pp. 3374-3380. http://dx.doi.org/10.1021/nn100335g

[2] Z. Yang and H. Chang, "CdHgTe and CdTe Quantum Dot Solar Cells Displaying an Energy Conversion Efficiency Exceeding 2\%," Solar Energy Materials and Solar Cells, Vol. 94, No. 12, 2010, pp. 2046-2051. http://dx.doi.org/10.1016/j.solmat.2010.06.013

[3] A. J. Nozik, “Quantum Dot Solar Cells,” Physica E: LowDimensional Systems and Nanostructures, Vol. 14, No. 1-2, 2002, pp. 115-120. http://dx.doi.org/10.1016/S1386-9477(02)00374-0

[4] A. J. Nozik, "Fundamental and Applications of QuantumConfined Structures,” NERL Publication, Vol. 3, 2007.

[5] B. E. Mccandless and J. R. Sites, "Cadmium Telluride Solar Cells,” Handbook of Photovoltaic Science and Engineering, John Wiley \& Sons Ltd., 2003, pp. 617-662.

[6] L. Tsakalakos, "Nanostructures for Photovoltaics," Materials Science and Engineering: R: Reports, Vol. 62, No. 6, 2008, pp. 175-189.

http://dx.doi.org/10.1016/j.mser.2008.06.002

[7] C. Grimes, "Titanium Dioxide Nanotube Arrays Improved Solar Cells,” SPIE Newsroom, 2008. http://dx.doi.org/10.1117/2.1200806.1148

[8] D. R. Baker and P. V. Kamat, "Photosensitization of $\mathrm{TiO}_{2}$ Nanostructures with CdS Quantum Dots: Particulate versus Tubular Support Architectures,” Advanced Functional Materials, Vol. 19, No. 5, 2009, pp. 805-811. http://dx.doi.org/10.1002/adfm.200801173

[9] D. Regonini, “Anodised $\mathrm{TiO}_{2}$ Nanotubes: Synthesis, Growth Mechanism and Thermal Stability,” Ph.D. Thesis, University of Bath, UK, 2008.

[10] G. K. Mor, O. K. Varghese, M. Paulose, K. Shankar and C. A. Grimes, "A Review on Highly Ordered, Vertically Oriented $\mathrm{TiO}_{2}$ Nanotube Arrays: Fabrication, Material Properties, and Solar Energy Applications,” Solar Energy Materials and Solar Cells, Vol. 90, No. 14, 2006, pp. 2011-2075. http://dx.doi.org/10.1016/j.solmat.2006.04.00 7

[11] M. Feteha, S. Ebrahim, M. Soliman, W. Ramdan and M. Raoof, "Effects of Mercaptopropionic Acid as a Stabilizing Agent and Cd:Te Ion Ratio on CdTe and CdHgTe Quantum Dots Properties,” Journal of Materials Science: Materials in Electronics, Vol. 23, 2012, pp.1938-1943. http://dx.doi.org/10.1007/s10854-012-0684-y

[12] M. T. Harrison, S. V. Kershaw, M. G. Burt and A. Eychmu, "Wet Chemical Synthesis and Spectroscopic Study of CdHgTe Nanocrystals with Strong Near-Infrared Luminescence,” Materials Science and Engineering, Vol. 70, 2000, pp. 355-360.

http://dx.doi.org/10.1016/S0921-5107(99)00254-8 